\title{
Marcos Janson
}

- Formado em Odontologia pela Universidade Paulista (UNIP - São Paulo).

- Especialista em Ortodontia pela FOB/USP - Bauru.

- Mestre em Ortodontia pela FOB/USP - Bauru.

- Professor e coordenador do Curso de Especialização em Ortodontia da ABCD - Salvador / BA.

- Ortodontista com clínica privada em Bauru / SP.

- Autor do livro "Ortodontia em Adultos e Tratamento Interdisciplinar" (Dental Press, 2008).

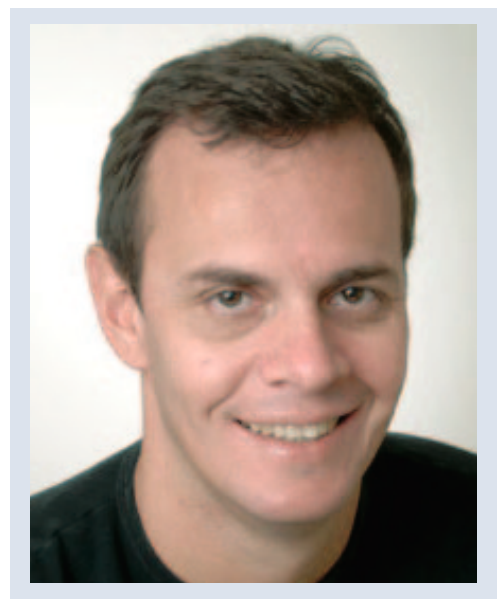

Se fosse apresentar o Prof. Marcos Janson há alguns anos, talvez tivesse que utilizar muitas linhas para convencer a comunidade ortodôntica brasileira de sua importância clínico-científica. Hoje, porém, torna-se uma tarefa extremamente simples, haja vista seu amplo reconhecimento perante os pares, por todo o Brasil. Tive a feliz oportunidade de conhecer o Marcos no curso de Mestrado na FOB-USP em 1992, onde fomos colegas. De lá para cá, a sua participação em uma clínica integrada de Odontologia (com também ilustres e conceituadíssimos profissionais) propiciou uma experiência interdisciplinar única, principalmente quanto à inter-relação Ortodontia, Periodontia e Prótese. Os anos de trabalho, observação e pesquisa trouxeram, em 2008, o inevitável: a publicação de seu livro "Ortodontia em adultos e tratamento interdisciplinar". O sobrenome Janson já era parte da história da Odontologia brasileira, devido às inúmeras contribuições de seu pai, o ilustre Prof. Dr. Valdir Janson, na área de reabilitação bucal. Assim como, na segunda geração, seu irmão Prof. Dr. Guilherme Janson (que também nos honra com sua participação nesta entrevista) tem levado o nome da Ortodontia a todos os cantos do mundo. Diz-se que educação vem de berço. O Prof. Marcos Janson respeita o ditado, mas com estrela própria!

Adilson Luiz Ramos

Em seu livro, você apresentou novos conceitos, tais como o conceito de unidade, a classificação do paciente orto-pério e a geometria do posicionamento dentário. Como você os define? Cibele Albergaria

Esses conceitos são importantes, pois ajudam no planejamento e permitem estabelecer diretrizes de objetivos e previsibilidade. O "Conceito de Unidade dente - osso - ligamento periodontal" se define pelo fato do dente e todo seu periodonto constituírem uma unidade inseparável, ou seja, informalmente costumo dizer que o periodonto é a roupa do dente e, assim como nossa roupa nos acompanha em nossos deslocamentos, o mesmo acontece com o dente (Fig. 1). Esse conceito permite a visualização de alterações do periodonto focando o deslocamento dentário, e é extremamente útil no tratamento orto-pério, onde o foco principal está na modificação da topografia óssea com intenção de manter ou reduzir defeitos. A própria colagem dos braquetes permite a visualização das alterações que ocorrerão. 
A classificação do paciente orto-pério foi criada baseada na experiência clínica do dia a dia e nas variações de objetivos e necessidades dos pacientes. No Tipo I, encontra-se o paciente que apresenta uma oclusão equilibrada (má oclusão ou não) e que apresenta um problema periodontal localizado. Nesses casos, a Ortodontia tem como objetivo único facilitar o tratamento periodontal, por meio da correção de defeitos ósseos (geralmente extrusão de algum dente comprometido); alinhar os dentes, para melhorar os espaços interproximais, facilitando a higiene e controle periodontal; ou providenciar o fechamento de diastemas, permitindo a confecção de contenção definitiva com o objetivo de eliminar o trauma oclusal secundário. Nesses casos, a montagem do aparelho se dá somente em pequenos segmentos do arco e não há o objetivo de alteração do relacionamento oclusal.
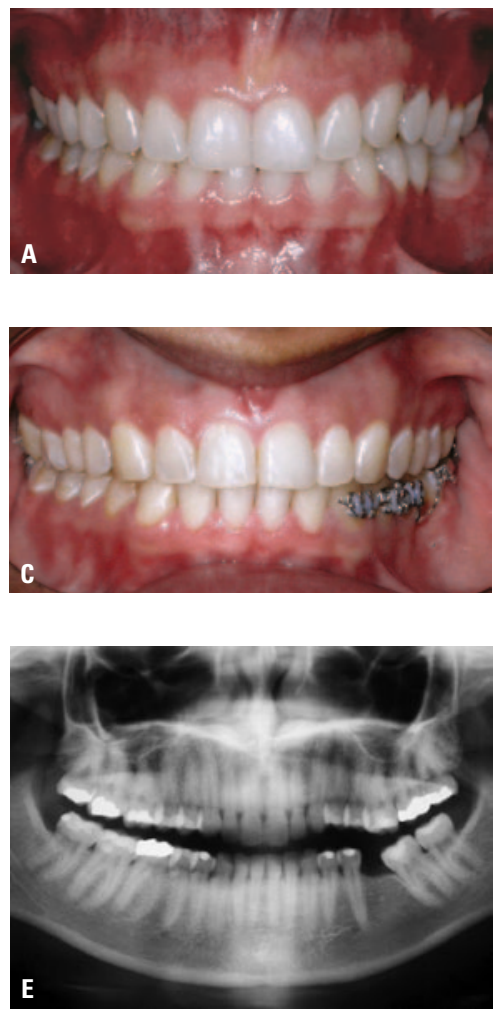

FIGURA 1 - A, B) Para exemplificar o conceito de unidade, pode-se notar, nesse caso, uma sinuosidade nos níveis dentários do lado esquerdo, devido à perda precoce do primeiro molar inferior esquerdo. Observa-se que a mesma curvatura delineada pelas incisais e oclusais é acompanhada pela gengiva. C, D) Após a correção ortodôntica, nota-se que tanto os dentes como a gengiva foram nivelados na mesma proporção. E, F) Radiograficamente, podese observar que o nível ósseo também acompanhou o dente, tanto na migração fisiológica quanto no movimento ortodôntico. Esse exemplo demonstra claramente o conceito de unidade: em condições de saúde periodontal, o periodonto acompanha os dentes em seus movimentos espontâneos ou induzidos. 
ao planejamento os objetivos reabilitadores no preparo de próteses e/ou implantes, aumentando, dessa forma, a complexidade e a necessidade de uma comunicação efetiva de todos os profissionais envolvidos.

A Geometria do Posicionamento Dentário é a compreensão do equilíbrio que existe entre o relacionamento dos dentes superiores e inferiores quando a relação dos caninos está adequada, ou seja, o ponto chave para o ótimo relacionamento anteroposterior é observar os caninos e saber quais atitudes devem ser tomadas para que esse se posicione na relação de Classe I, entre o canino e o pré-molar inferior. Partindo desse princípio e levando-se em consideração a linha média superior, para decisão de extrações uni ou bilaterais na maxila, o planejamento da movimentação dentária e ancoragem necessária fica evidente. Com o entendimento desse conceito, torna-se muito simples o tratamento de casos atípicos, como as ausências de incisivos superiores ou inferiores, ou mesmo de caninos, pois renomeiam-se os dentes e indentifica-se qual fará o papel de canino (harmonizando a relação dos seis dentes anteriores superiores e inferiores) e, a partir daí, o que parecia complexo torna-se extremamente fácil. Tenho usado essa técnica nos meus ensinamentos e a evolução do planejamento e a visualização da oclusão final têm facilitado o dia a dia de muitos colegas.

\section{Quais são as suas diretrizes para o planeja- mento orto-pério? E qual o seu protocolo de tratamento? Cibele Albergaria}

As diretrizes do planejamento orto-pério visam, todas elas, primariamente aumentar a longevidade dos dentes, melhorando ou mantendo a situação do periodonto. Para isso, o tratamento ortodôntico deve visar, em ordem de prioridade: a eliminação de traumas oclusais primários e secundários, a diminuição de defeitos ósseos por meio de movimentos extrusivos, a oclusão funcional mutuamente protegida (quando não for possivel atingi-la devido à limitação de movimentos, uma placa miorrelaxante deve ser confeccionada) e posteriormente, se possível e não necessariamente, buscamos os objetivos tradicionais da Ortodontia, como as seis chaves de oclusão.

O protocolo de tratamento do paciente ortopério consiste em trabalhar todo o tempo em ambiente sadio, livre de inflamação periodontal. Para isso, o paciente é encaminhado ao periodontista no início e no decorrer do tratamento, a cada três ou quatro meses aproximadamente, para que sejam realizados procedimentos de raspagem, profilaxia e alisamento radicular. Após o tratamento, deve ser plenamente esclarecido ao paciente que o tratamento ortodôntico está finalizado, porém o tratamento periodontal deve ter continuidade, para que o periodonto possa se manter em condições de saúde. Geralmente, faço um encaminhamento ao periodontista, relatando o final do tratamento e transferindo definitivamente o paciente. Esse encaminhamento é assinado pelo profissional e pelo paciente, para que fique registrado. Outro dado importante é utilizar no diagnóstico, no início, no meio e final de tratamento, radiografias periapicais padronizadas, para que se tenha o registro completo das alterações provocadas pela movimentação ortodôntica.

O que diferencia a movimentação ortodôntica em pacientes adultos sem problemas periodontais e em pacientes adultos comprometidos periodontalmente? Cibele Albergaria

O que as diferencia, primeiramente, são os objetivos, pois, diferentemente da Ortodontia convencional - que tem o foco direcionado para as coroas dentárias, suas inter-relações e o relacionamento com os tecidos moles da face -, o tratamento orto-pério foca o periodonto, buscando melhorar as relações dos dentes com o seu periodonto, priorizando a longevidade dos dentes. Do ponto de vista da movimentação em si, existem algumas limitações de movimento, devido ao maior risco causado pela concentração de forças próximas ao ápice, resultado da diminuição do nível ósseo.

No tratamento das discrepâncias esqueléticas, que indicadores utiliza para escolher 
entre o planejamento ortodôntico e ortodôntico-cirúrgico? Cibele Albergaria

Os indicadores que utilizo são os seguintes:

a) Queixa do paciente - é o parâmetro mais importante, pois está relacionado com a satisfação ao final do tratamento. Se a queixa principal é direcionada para alguma característica que não é possível de ser alterada pela movimentação, indico a cirurgia.

b) Restrição mecânica - se a má oclusão apresenta-se muito discrepante, determinando dificuldade mecânica ou reconhecida instabilidade dos resultados, direciono para a cirurgia. Um exemplo seriam as más oclusões com envolvimento vertical, como o excesso ou deficiência vertical da maxila e mordidas abertas em adultos.

c) Ausência dos traços faciais e limitação para obtê-los - a percepção de normalidade da face, principalmente por leigos, se dá pela presença dos traços característicos da face, como: perfil reto ou convexo, lábio superior à frente do ponto subnasal e na mesma linha ou à frente do lábio inferior, presença do sulco mentolabial, definição do mento e linha mento-pescoço. Esses traços, mesmo pouco definidos, conferem a forma normal à face, a qual é bem recebida pela sociedade. Em sua ausência, causam a percepção de anormalidade, muitas vezes não identificando-se o porquê, porém debilitando a estética facial. Na impossibilidade da correção por meios meramente ortodônticos, recomendo a cirurgia. $\mathrm{O}$ exemplo mais clássico são os casos de Classe II com retrusão mandibular e ausência de linha mento-pescoço. Nessas situações prefiro não realizar compensações.

Você publicou recentemente, na Revista Clínica de Ortodontia Dental Press, uma Dica Clínica sobre os levantes fixos para abrir a mordida. Qual o tempo médio que mantém esses levantes, e o que tem percebido em termos de estabilidade desse aumento da dimensão vertical a longo prazo? Adilson Luiz Ramos

Essa pergunta é pertinente, pois esse recurso tem gerado certa confusão. Os levantes de mordidas podem ser realizados de duas formas: na região posterior, com aplicação de resina nas superfícies oclusais dos molares, ou na região anterior, com batentes posicionados na superfície palatina dos incisivos. Em ambos os casos não há intenção, em nenhum momento, de provocar o aumento da dimensão vertical do paciente e sim, unicamente, dar espaço para a colagem dos acessórios inferiores nos casos de sobremordidas, para que a curva se Spee seja corrigida o mais rápido possível. O que gera alguma controvérsia é o levantamento anterior, pois, permitindo a desoclusão dos posteriores, supõe-se que haja extrusão e aumento vertical. No entanto, o tempo de utilização do levante é, em média, de quatro meses e, levando-se em consideração que após esse período o tratamento se prolonga por mais 20 meses aproximadamente, alguma recidiva, se houvesse, ocorreria durante o tratamento. Vale lembrar que o fator determinante para a ocorrência de sobremordida na região anterior é a falta de contato imediato dos dentes anteriores, portanto, a checagem da oclusão anterior com o papel celofane ao final do tratamento é muito importante. A checagem é realizada da seguinte forma: o celofane é interposto entre os incisivos e pede-se para o paciente morder. $\mathrm{O}$ celofane deve ficar preso entre os dentes e, ao forçar a sua retirada, ele sai sem ser rasgado. Se o celofane rasgar é porque existe contato prematuro, devendo ser ajustado. Se o celofane não ficar preso entre os dentes é porque não há contato e, nesses casos, pode-se esperar que a sobremordida recidive. No longo prazo, ainda não tenho resultados para fornecer, mas em curto prazo apresentam-se estáveis. Nas figuras 2 e 3 são apresentadas as duas possibilidades citadas no texto.

No congresso da Dental Press, você explorou brilhantemente as indicações de intrusão de molares em casos periodontais (ou não) - inclusive impressionando o Prof. Marco Rosa (convidado internacional). Poderia compartiIhar esse tópico com os nossos leitores? Adilson Luiz Ramos

Um dos parâmetros de normalidade do periodonto é a sua planificação, ou seja, que o osso esteja plano entre os dentes e, preferencialmente, 

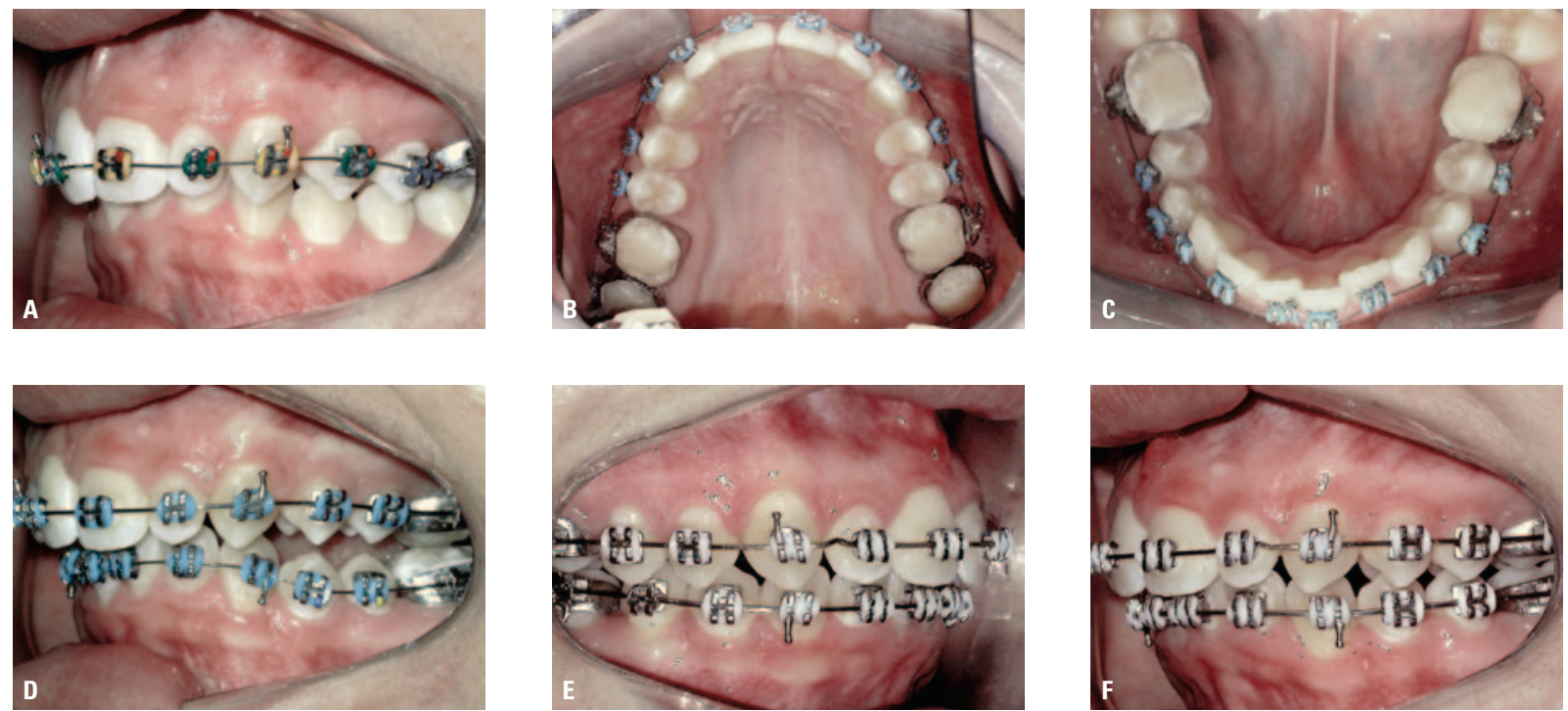

FIGURA 2 - A) Impossibilidade de colagem dos acessórios inferiores devido à sobremordida. B, C) Presença de resina na superfície oclusal dos primeiros molares superiores e inferiores, para desoclusão anterior. D) Instalação dos acessórios do arco inferior colados pós-desoclusão anterior. E, F) Fotos laterais após seis meses, quando foi removida a resina dos dentes posteriores. Nota-se que já existe oclusão nos dentes posteriores e os braquetes inferiores não contatam os dentes superiores.
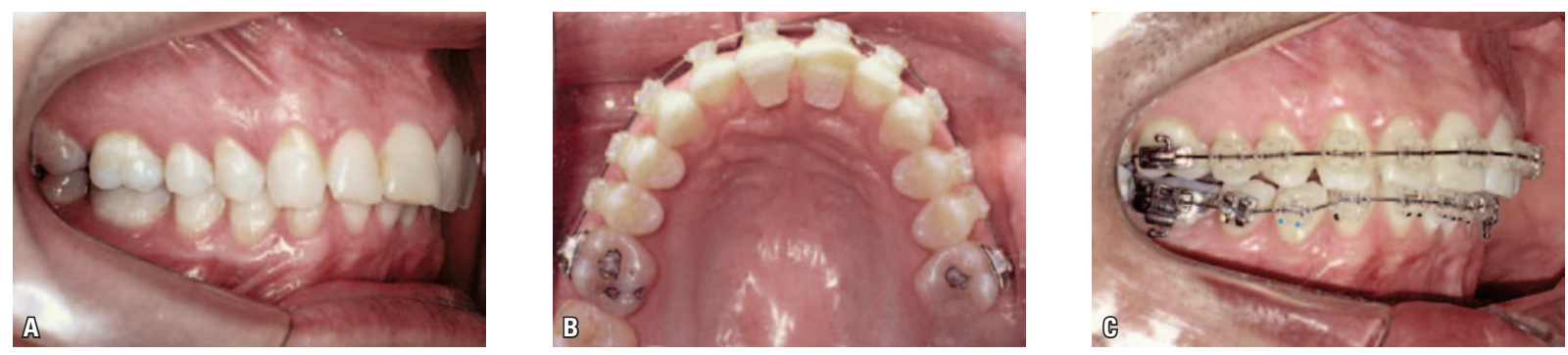

FIGURA 3 - A) Representação de sobremordida em caso de Classe II, divisão 1, impossibilitando a colagem imediata dos acessórios inferiores. B) Triângulos de resina (JANPI) colados às superfícies palatinas dos incisivos superiores para "levantar a mordida". C) Colagem imediata dos acessórios inferiores, após o levantamento. 0 fator primordial da correção é a ação imediata dos fios na planificação da curva de Spee. À medida que os braquetes dos caninos inferiores se distanciam do contato com os superiores, a resina vai sendo desgastada, até haver o contato dos dentes posteriores.

a uma distância da junção-cemento-esmalte de $1 \mathrm{~mm}$ em pacientes jovens, e de 2 a $3 \mathrm{~mm}$ em adultos. Levando-se em consideração essas características, ao pensar na intrusão de um dente que se encontra extruído, primeiramente deve ser avaliado como o osso se encontra. Três situações distintas podem ocorrer:

a) Se o dente extruiu e o periodonto acompanhou (extrusão fisiológica), haverá uma rampa positiva em relação aos dentes adjacentes e, ao intruí-lo, se restabelecerá a normalidade da topografia óssea, sendo, portanto, indicada (Fig. 4).

b) $\mathrm{O}$ dente extruiu e o osso não acompanhou, permanecendo plano (extrusão patológica). Nesses casos, a intrusão causaria um defeito vertical em relação aos dentes adjacentes, piorando o quadro periodontal. O correto, nesse caso, é desgastar o dente e preservar o nível ósseo (Fig. 5).

c) $\mathrm{O}$ dente extruiu e ao seu redor existe um defeito ósseo vertical. O mais indicado é a extrusão do dente e o desgaste da coroa, providenciando a correção do defeito. Outra possibilidade é, se o defeito for de três paredes, intruir o dente para aumentar o defeito e em seguida promover a regeneração óssea guiada, por meio de enxerto ósseo e membrana. 

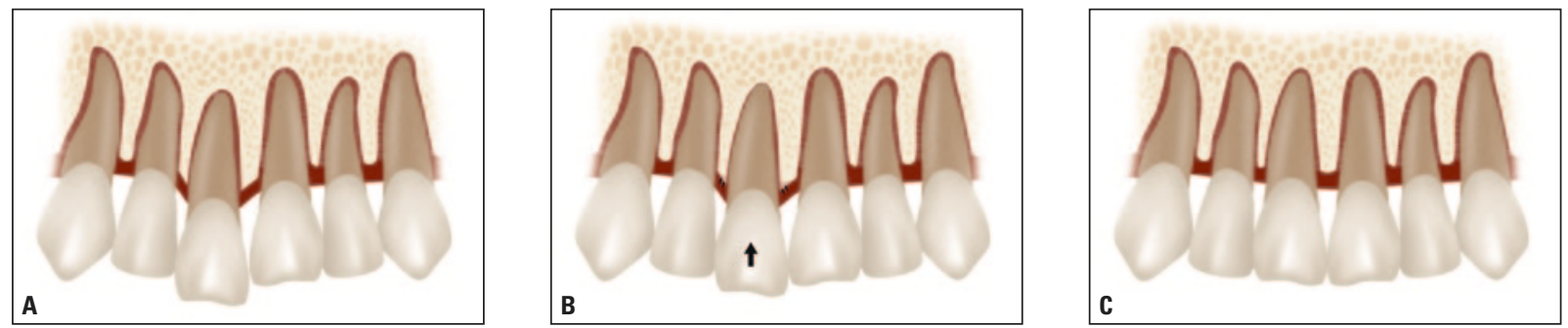

FIGURA 4 - A) Caracterização da migração fisiológica do incisivo central direito. Observa-se que o dente está extruído em relação aos seus adjacentes e todo o seu periodonto o acompanha, ou seja, o nível de inserção conjuntiva e também o posicionamento da gengiva em relação à junção cemento-esmalte permanecem inalterados. De acordo com o conceito de unidade, conforme se aplica nesse dente uma força intrusiva, as fibras dentogengivais e dentocrestais serão tensionadas em direção apical (B) e deslocarão o periodonto junto com o dente (C), promovendo o nivelamento dente e osso.
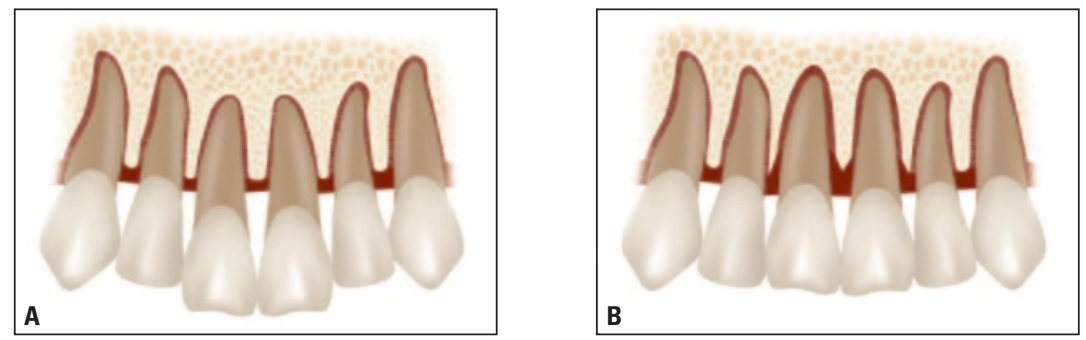

FIGURA 5 - A) Desenho representando a extrusão patológica de dois incisivos superiores com perda óssea horizontal. B) Ao intruir os dentes, as cristas ósseas são tensionadas apicalmente e os defeitos horizontais são transformados em verticais, piorando o quadro periodontal.

\section{Qual(is) é(são) seu(s) parâmetro(s) para os limites da vestibularização dos incisivos infe- riores? Adilson Luiz Ramos}

Nós, ortodontistas, estamos sempre em busca de parâmetros precisos para definir nossa mecânica. No passado, ficamos durante muito tempo restritos às medidas cefalométricas, mas como não pode haver uma só medida para formas de faces e maxilares tão díspares e como trabalhos mais recentes têm demonstrado, a inclinação dentária para lingual na compensação da Classe III ou vestibular na compensação da Classe II tem seguido outras diretrizes. Para avaliar a possibilidade de inclinação vestibular em meus pacientes, o meu referencial é a situação do periodonto na vestibular. Quando a faixa de gengiva ceratinizada é de $2 \mathrm{~mm}$ ou mais e a espessura vestibular da gengiva é igual ou maior que $1 \mathrm{~mm}$, realizo o movimento com segurança. Do contrário, ou é requisitado, previamente, um enxerto gengival livre ou, então, aborto o procedimento e replanejo a mecânica, o que muito provavelmente, nas Classes II mais severas, determinará um tratamento cirúrgico.
Primeiramente, meus cumprimentos pelo excelente trabalho que vem desenvolvendo. Apesar de saber que o foco principal de seu trabalho é o tratamento de adultos, qual a sua opinião sobre a utilização de dispositivos temporários de ancoragem (DTA) em pacientes em crescimento, especialmente na fase de dentadura mista? Luiz Sergio Carreiro

Obrigado pelo cumprimento. Acredito que os DTA têm seu lugar no tratamento dos pacientes na dentadura mista. Situações que parecem ser promissoras são os casos de protração maxilar, para diminuir o componente dentário e acentuar o movimento ortopédico, e também em casos de agenesias onde os espaços não poderão ser fechados da forma tradicional (agenesias inferiores na Classe II e superiores na Classe III), sendo, portanto, indicada a mesialização dos dentes. A dificuldade em ambas as situações é a localização dos dispositivos (mini-implantes), visto que, nessa fase, os dentes permanentes ainda não irrompidos, ocupam os espaços tradicionalmente utilizados para sua colocação. 
As miniplacas são utilizadas em sua rotina clínica? Caso sim, em qual(is) situação(ões)? Luiz Sergio Carreiro

Não utilizo as miniplacas, apesar de achá-las extremamente eficazes. Tenho preferência pela utilização dos mini-implantes.

\section{A utilização rotineira dos DTA proporcionou uma diminuição do número de pacientes tra- tados cirurgicamente em sua clínica? Luiz Ser- gio Carreiro}

Não, os pacientes com deformidades faciais e que apresentam queixas relacionadas às estruturas da face, às quais há limitações ortodônticas para modificá-las, continuam normalmente sendo indicados para cirurgia. O que tenho realizado, ainda em pequena escala e em gravidade moderada, esperando dados mais confiáveis da comunidade científica, é o fechamento de mordidas abertas pela intrusão dos posteriores. Se for comprovada a estabilidade em longo prazo desses resultados, acredito que uma parcela considerável de pacientes que apresentam mordidas abertas esqueléticas poderá ter a alternativa de tratamento ortodôntico em vez da cirúrgica. Mas, por enquanto, permaneço aguardando dados mais confiáveis. A ressalva que faço são as possibilidades de correção do plano inclinado frontal da maxila. Quando a queixa se limita mais ao sorriso e a estética facial não apresenta-se muito comprometida, é uma situação em que conseguimos um bom resultado ortodôntico, sem recorrer à cirurgia (Fig. 6).

Em todos os eventos da área e periódicos, o assunto DTA tem sido muito debatido e observa-se a utilização dos mesmos para todos os tipos de problemas verticais, transversais e anteroposteriores. Existe alguma situação na qual você não os indica, e por qual motivo? Luiz Sergio Carreiro

Como relatado na pergunta anterior, faço algumas ressalvas quanto aos problemas verticais. Outra alternativa que não me agrada muito são as distalizações com mini-implantes, principalmente bilaterais e maiores que $3 \mathrm{~mm}$. Nesses casos, continuo achando que as melhores alternativas
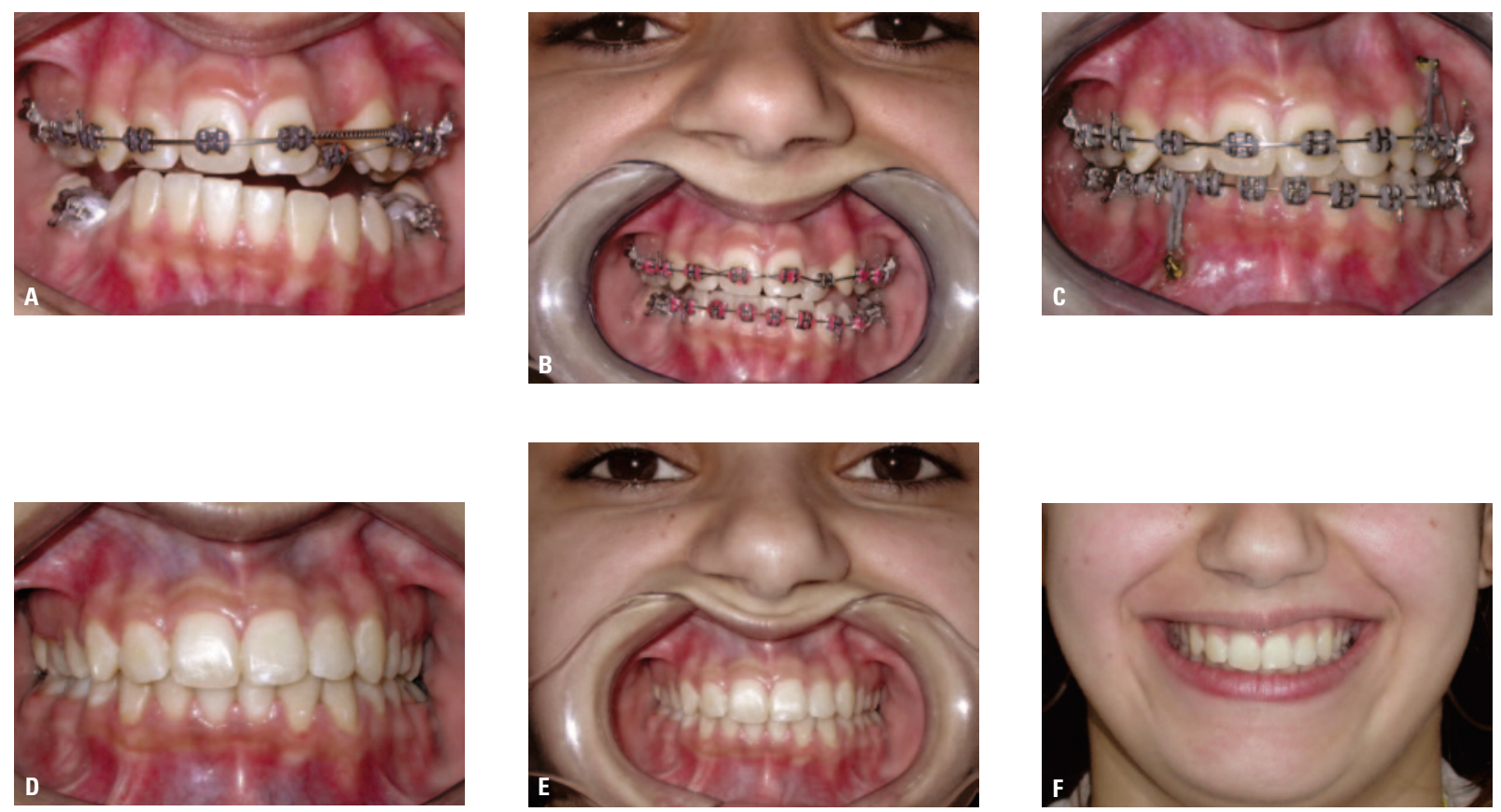

FIGURA 6 - A) Inclinação notável do plano anterior na mandíbula e na maxila. B) Relação de inclinação com referência ao plano dos olhos. C) Mini-implantes do lado inferior direito e superior esquerdo, para intrusão dos segmentos e planificação interarcos. D) Oclusão final. E) Relação final da inclinação dos planos com referência ao plano dos olhos. F) Apesar de mantida a assimetria do tecido mole no sorriso, o relacionamento com os dentes é bastante harmonioso. 
são as extrações de pré-molares (com resultados faciais estéticos iguais, pois os caninos finalizam na mesma posição) ou a utilização de elásticos de Classe II ou III, pois requerem menor tempo de tratamento, simplificam a mecânica e apresentam menor potencial de recidiva

\section{Quais são as situações em que podemos "for- mar" osso com a movimentação ortodôntica?} Guilherme Janson

As situações que podemos "formar" osso em Ortodontia são todas aquelas onde provocamos a tensão do ligamento periodontal. No aspecto vertical, utilizamos a extrusão dentária para posicionar o osso mais coronalmente, para reduzir defeitos ósseos verticais e/ou horizontais, em dentes isolados ou em blocos. A mesma situação pode ser desejada se os dentes estão condenados e se planeja a substituição por implantes. Especificamente nessa situação, a presença de um alvéolo intacto de pelo menos $4 \mathrm{~mm}$ apicalmente é necessária, para que se possa trazer todo o osso para o nível coronal e providenciar a colocação dos implantes na posição apicocoronal desejada (Fig. 7).

No aspecto horizontal, utiliza-se a movimentação mesiodistal do dente em rebordo atrófico para promover a formação de rebordo ósseo íntegro na face oposta, permitindo, dessa forma, a colocação de implante osseointegrado nessa área.

\section{A periodontite juvenil impossibilita o trata- mento ortodôntico? Guilherme Janson}

A periodontite juvenil não impossibilita o tratamento, desde que esteja controlada e supervisionada de perto pelo periodontista. Como sua característica principal é a destruição óssea na região de incisivos e molares, o foco deve ser a preservação do nível ósseo nessas áreas, por meio da estabilização dos dentes, após providenciar os pontos de contato ou, se a situação já é muito
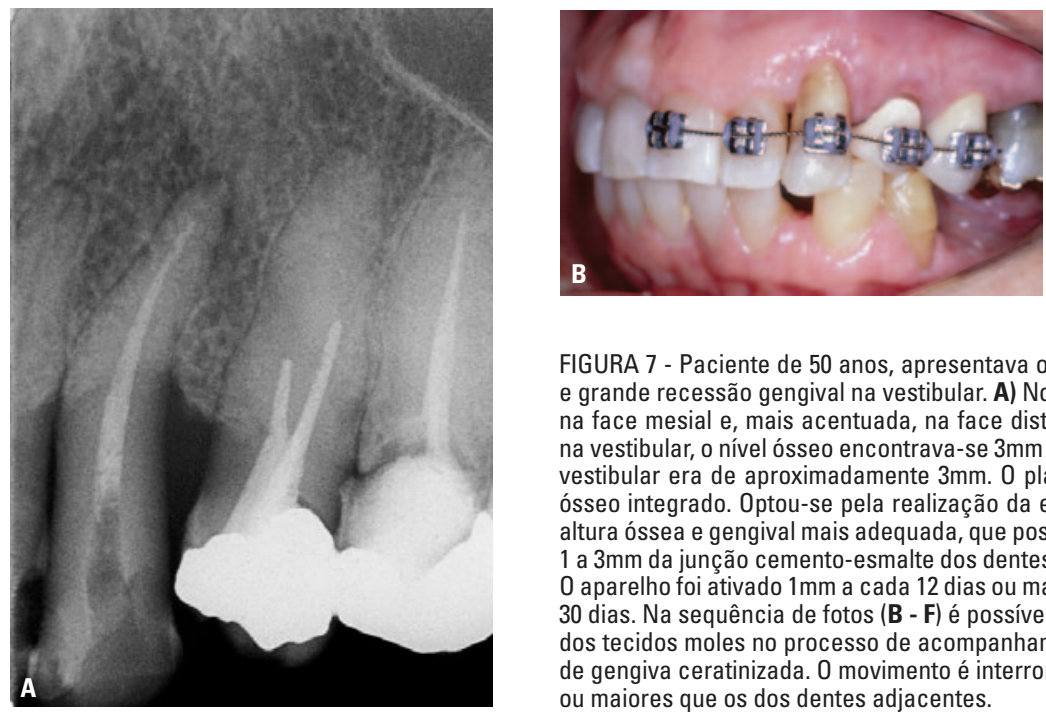

FIGURA 7 - Paciente de 50 anos, apresentava o canino superior esquerdo com mobilidade de grau 2 e grande recessão gengival na vestibular. A) No exame radiográfico observa-se perda óssea vertical na face mesial e, mais acentuada, na face distal. Por meio de sondagem clínica, constatou-se que, na vestibular, o nível ósseo encontrava-se 3mm abaixo no nível gengival, ou seja, o remanescente por vestibular era de aproximadamente $3 \mathrm{~mm}$. 0 planejamento envolvia a sua substituição por implante ósseo integrado. Optou-se pela realização da extração lenta do dente, como meio de se conquistar altura óssea e gengival mais adequada, que possibilitasse a colocação do implante na altura ideal, de 1 a 3mm da junção cemento-esmalte dos dentes vizinhos, propiciando função e estética satisfatórias. 0 aparelho foi ativado $1 \mathrm{~mm}$ a cada 12 dias ou mais, sendo que algumas vezes o intervalo foi superior a 30 dias. Na sequência de fotos (B - F) é possível verificar o processo de ativação e o comportamento dos tecidos moles no processo de acompanhamento do movimento, sendo nítido o aumento da faixa de gengiva ceratinizada. 0 movimento é interrompido quando os níveis gengival e ósseo estão iguais ou maiores que os dos dentes adjacentes.

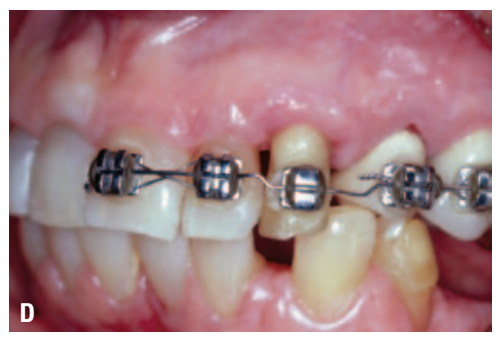

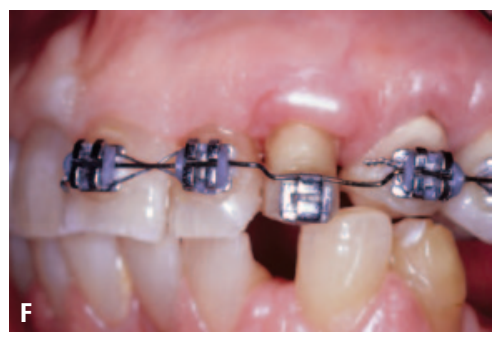



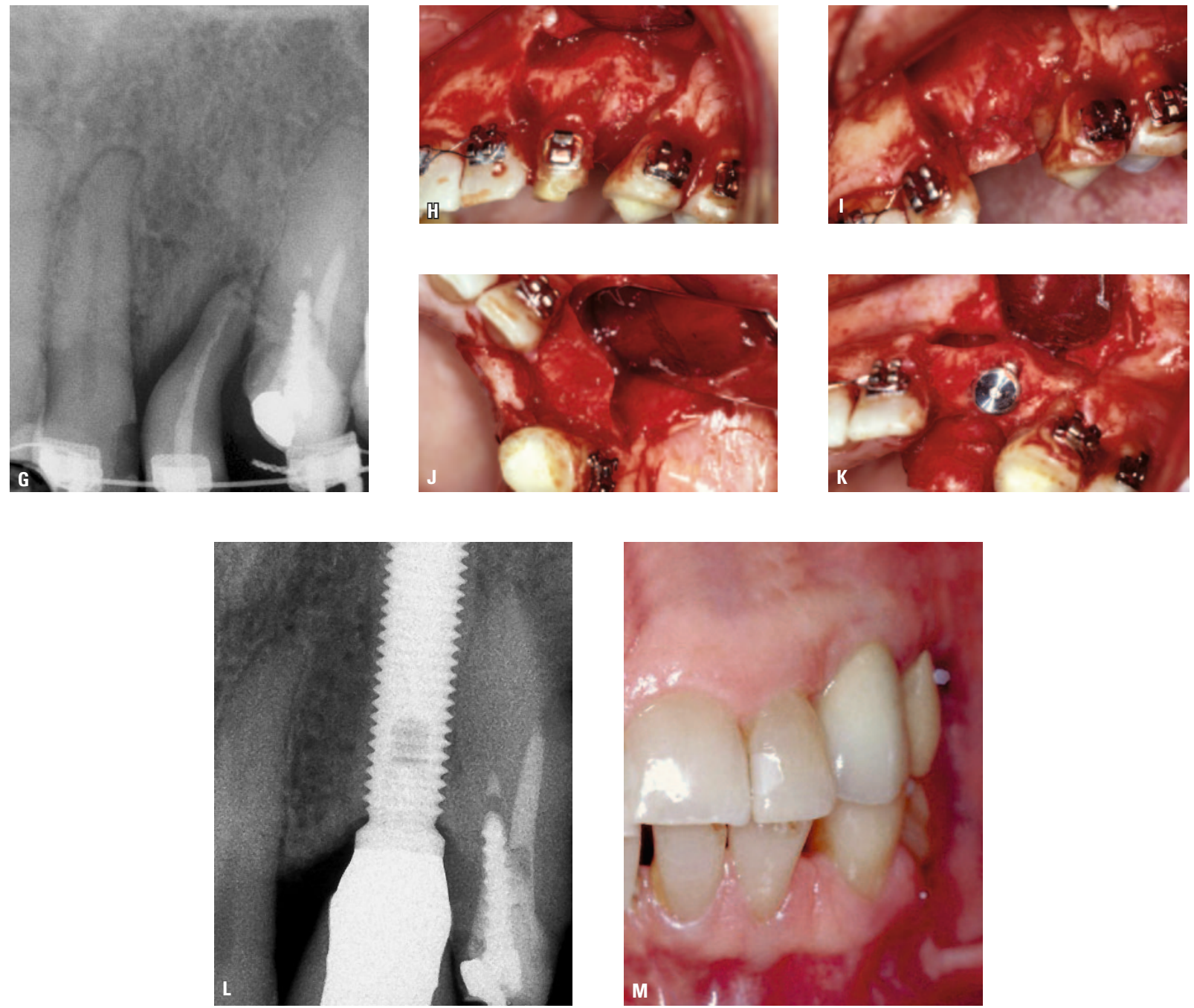

FIGURA 7 (continuação) - Em (G) nota-se como o osso está nivelado na mesial e distal, eliminando, dessa forma, os defeitos verticais outrora presentes. Depois de atingido o objetivo almejado, o dente foi estabilizado por um período de 4 meses, período esse sucedido pela cirurgia de extração do dente e fixação do implante. H) Na sequência, o campo aberto com o dente ainda em posição evidencia a fenestração na vestibular, que aproximava-se do ápice. I) Após a extração, denota-se a neoformação óssea na área coronal, com o direcionamento vertical evidente das espículas ósseas e o nível ósseo mesiodistal mais coronal do que os dentes vizinhos, caracterizando excesso de osso em uma área que antes se mostrava deficiente. J) Em vista oclusal, seguindo a curvatura do arco, observa-se espessura óssea suficiente para a fixação do implante. K) Para que ficasse a $3 \mathrm{~mm}$ da junção cemento-esmalte dos dentes vizinhos, algumas roscas do implante ficaram expostas na vestibular, porém numa superfície muito pequena, que pôde facilmente ser recoberta com osso autógeno da área da crista óssea mesial, que apresentava altura em excesso. L) Na radiografia final, após 1 ano, pode-se comprovar a osseointegração do implante e em (M) o resultado estético final.

grave, com remanescente ósseo muito reduzido no ápice, promover a extrusão lenta desses dentes enquanto a inserção remanescente ainda permite, para substitui-los por implantes. Uma outra proposta é intruir os dentes com defeitos verticais (se estiverem extruídos) para promover a regeneração guiada.

\section{Como determinar se um paciente com envol-} vimento periodontal poderá ser submetido ao tratamento ortodôntico? Guilherme Janson

Todo paciente com envolvimento periodontal pode ser submetido ao tratamento ortodôntico, desde que o periodonto esteja saudável e haja controle pelo periodontista e higiene adequada. 


\section{BIBLIOGRAFIA RECOMENDADA}

1. ALLAIS, D. MELSEN B. Does labial movement of lower incisors influence the level of the gingival margin? A case-control study of adult orthodontic patients. Eur. J. Orthod., Oxford, v. 25, no. 4, p. 343-352, Aug. 2003.

2. HANDELMAN, C. Orthodontic care of the periodontally compromised patient followed long term: Part I. Maximizing favorable outcomes. World J. Orthod., Boulder, v. 2, no. 2 , p. 127-141, 2001.

3. JANSON, M. Ortodontia em adultos e tratamento interdisciplinar. Maringá: Dental Press, 2008.

4. JANSON, M.; PITHON, G. Alternativas para acelerar a colagem dos acessórios inferiores em casos com sobremordida profunda. Rev. Clín. Ortodon. Dental Press, Maringá, v. 7 , n. 3, p. 27-36, jun./jul. 2008.

5. JANSON, M. R. P.; JANSON, R. R. P.; MARTINS, P. F.

Tratamento interdisciplinar I: verticalização de molares. Considerações clínicas e biológicas. Rev. Dental Press Ortodon. Ortop. Facial, Maringá, v. 6, n. 3, p. 87-104, maio/jun. 2001.

6. JANSON, M.; PASSANEZZI, E.; JANSON, R. R. P.; PINZAN, A. Tratamento interdisciplinar II: alterações verticais no periodonto induzidas ortodonticamente. Rev. Dental Press Ortodon. Ortop. Facial, Maringá, v. 7, n. 4, p. 85-105, jul./ago. 2002.

7. LIN, J. C.; YEH, C. L.; LIOU, E. J.; BOWMAN, S. J. Treatment of skeletal-origin gummy smiles with miniscrew anchorage. J. Clin. Orthod., Boulder, v. 42, no. 5, p. 285-296, 2008

8. MELSEN, B.; AGERBAEK, N.; MARKENSTAM, G. Intrusion of incisors in adult patients with marginal bone loss. Am. J. Orthod. Dentofacial Ortop., St. Louis, v. 96, no. 3, p. 232-241, 1989

9. MELSEN, B.; AGERBAEK, N.; ERIKSEN, J.; TERP, S. New attachment through periodontal treatment and orthodontic intrusion. Am. J. Orthod. Dentofacial Ortop., St. Louis, v. 94, no. 2, p. 104-116, Aug. 1988.

10. MURAKAMI, T.; YOKOTA, S.; TAKAHAMA, Y. Periodontal changes after experimentally induced intrusion of the upper incisors in macaca fuscata monkeys. Am. J. Orthod. Dentofacial Ortop., St. Louis, v. 95, no. 2, p. 115-126, Feb. 1989.

11. PARK, Y. C.; LEE, H. A.; CHOI, N. C.; KIM, D. H. Open bite correction by intrusion of posterior teeth with miniscrews. Angle Orthod., Appleton, v. 78, no. 4, p. 699-710, Jul. 2008.

12. PASSANEZI, E.; JANSON, M.; JANSON, G.; SANT'ANNA A. P.; FREITAS, M. R.; HENRIQUES, J. F. C. Interdisciplinary treatment of localized juvenile periodontitis: a new perspective to an old problem. Am. J. Orthod. Dentofacial Ortop., St. Louis, v. 131, no. 2, p. 268-276, Feb. 2007.

13. RABIE, A. B. M.; GILDENHUYS, R.; BOISSON, M. Management of patients with severe bone loss: bone induction and orthodontics. World J. Orthod., Boulder, v. 2, no. 2, p. 142-153, 2001.

14. VADEN, J. Case reports: Achievable optimum. World J. Orthod., Boulder, v. 3, no. 1, p. 41-49, 2002

15. XUNA, C.; ZENG, X.; WANG, X. Microscrew anchorage in skeletal anterior open-bite treatment. Angle Orthod. Appleton, v. 77, no. 1, p. 47-56, Jan. 2007.

\section{Adilson Luiz Ramos}

- Mestre em Ortodontia pela FOB-USP.

- Doutor em Ortodontia pela Universidade Estadual Paulista Júlio de Mesquita Filho - Unesp/Araraquara. - Professor adjunto de Ortodontia da Universidade Estadual de Maringá (UEM).

- Coordenador do Curso de Mestrado Acadêmico em Odontologia Integrada da UEM.

- Ex-editor da Revista Dental Press de Ortodontia e Ortopedia Facial (2003 - 2006).

- Professor da Escola de Aperfeiçoamento Profissional da Associação Brasileira de Odontologia.

\section{Cibele Albergaria}

- Especialista em Ortodontia e Ortopedia Facial pela ABO-DF.

- Especialista em Odontopediatria pela APCD-Bauru/SP.

- Coordenadora Científica do $7^{\circ}$ Congresso da ABOR/2009.

\section{Guilherme Janson}

- Mestre e doutor em Ortodontia pela FOB-USP.

- Pós-doutorado em Ortodontia pela University of Toronto (1991).

- Professor titular da FOB-USP.

- Revisor dos periódicos AJODO, Angle Orthodontist, Indian Journal of Dental Research, Orthodontics and Craniofacial Research, Revista de Saúde Pública / Journal of Public Health, Revista Dental Press de Ortodontia e Ortopedia Facial, Journal of Applied Oral Science, Revista Clínica de Ortodontia Dental Press, Medical Science Monitor, World Journal of Orthodontics, Journal of Dental Research, Journal of Orthodontics, membro do corpo editorial e revisor da revista Ortodontia (São Paulo) e membro do corpo editorial da Open Journal of Dentistry Insights.

\section{Luiz Sergio Carreiro}

- Mestre em Odontologia pela FOB-USP.

- Doutor em Odontologia pela Universidade Estadual Paulista Júlio de Mesquita Filho - Unesp.

- Professor adjunto da disciplina de Ortodontia da Universidade Estadual de Londrina.

- Consultor científico da Revista Dental Press de Ortodontia e Ortopedia Facial.
Endereço para correspondência

Marcos Janson

E-mail: jansonm@uol.com.br

Site: www.mjanson.com.br 